Artikel Penelitian

\title{
Studi Experimental Terhadap Perpindahan Kalor Pada Tumbukan Multiple Droplets Dengan Variasi Frekuensi Tetesan
}

\author{
Indro Pranoto*, Dannys Arif Kusuma, Teguh Wibowo, Fauzun, Deendarlianto dan Indarto \\ Departemen Teknik Mesin dan Industri, Fakultas Teknik, Universitas Gadjah Mada, Jl. Grafika No. 2, Yogyakarta 55281, Indonesia
}

INFORMASI ARTIKEL

Sejarah Artikel:

Diterima Redaksi: 1 Oktober 2018

Revisi Akhir: 24 Oktober 2018

Diterbitkan Online: 29 Oktober 2018

KATA KUNCI

Multiple droplet

Drop frequency

Spreading ratio

Heat transfer coefficient

Cooling technology

KORESPONDENSI

*E-mail: indro.pranoto@ugm.ac.id

\begin{abstract}
A B S T R A C T
The effect of drop frequencies and surface temperature on the maximum spreading ratio, heat transfer rate and heat transfer coefficient of convection have been studied experimentally. The experiments were carried out by investigating different values of drop frequencies at 250, 400 and 600 drops/minute. The surface material of stainless steel with a temperature range of $120^{\circ} \mathrm{C}$ to $200^{\circ} \mathrm{C}$ was used in the study. An image processing technique was used to measure the diameter of droplets that were captured by using a highspeed camera. The results of the study show that by increasing frequency of drops has improved significantly the maximum spreading ratio, heat transfer rate and heat transfer coefficient of convection. The results also shown that by increasing the drop frequency has increased accordingly the droplet contact with the surface. It was found that, at higher surface temperature has contributed to the increase of the heat transfer rate and convection heat transfer coefficient. This study suggest that the peak and wetting limit conditions has occurred at the surface temperature of $180^{\circ} \mathrm{C}$.
\end{abstract}

\section{PENDAHULUAN}

Sistem pendingin yang inovatif dan efektif yang mampu mendisipasi kalor dengan fluks kalor yang tinggi sangat diperlukan pada suatu sistem pendinginan pada masa sekarang dan akan datang, khususnya pada beberapa aplikasi yang memerlukan proses pendinginan yang efektif, seperti proses reaksi inti nuklir, pembentukan material, proses quenching, proses permesinan, serta pendinginan berbagai komponen elektronik yang semakin maju. Dalam menjaga kestabilan dan efisiensi kerja suatu sistem tersebut dapat dilakukan dengan menjaga temperatur sistem pada kondisi optimal. Metode pendinginan dua-fasa seperti pool dan flow boiling [1-2] serta spray cooling merupakan teknik pendinginan yang menjanjikan untuk menjawab tantangan kebutuhan pendinginan berbagai produk dan sistem yang menghasilkan fluks kalor tinggi di masa yang akan datang. Cheng dkk. [3] menyatakan bahwa metode spray cooling mampu menghasilkan koefisien perpindahan kalor konveksi tertinggi dibandingkan dengan metode pembuangan kalor lainnya. Sehingga spray cooling mampu membuang kalor berfluks kalor tinggi dari sebuah sistem, lebih efektif dibandingkan dengan metode pembuangan kalor lainnya. Spray cooling juga dianggap paling sesuai untuk sistem yang membutuhkan fluks kalor yang tinggi [4]. Metode spray cooling tidak hanya 
mampu membuang kalor secara tinggi tetapi dengan pengaturan waktu, tekanan, kecepatan penyemprotan juga mampu mengontrol laju pendinginan yang diinginkan [5-7]. Bernadin dkk. [5] melakukan analisa pada spray cooling dengan pendekatan sederhana yaitu mengamati tumbukan tetesan tunggal (single droplet) pada permukaan padat yang dipanaskan. Hasil dari eksperimen tersebut adalah karakteristik perpindahan kalor pada single droplet yang kemudian digunakan untuk memprediksi karakteristik perpindahan kalor pada proses spraying.

Droplet adalah sebuah kumpulan cairan yang terikat oleh tegangan permukaan yang membentuk seperti bola. Droplet dapat diproduksi dengan mengalirkan cairan secara perlahan di dalam tabung yang berdiameter kecil seperti jarum yang berlubang. Pada bagian ujung tabung kecil tersebut akan terbentuk pendant drop. Ketika droplet membesar dan telah mencapai massa tertentu. Droplet akan melepaskan diri dan jatuh bebas. Jika droplet tersebut dijatuhkan dengan selisih waktu tertentu secara terus-menerus pada suatu permukaan maka disebut multiple droplets. Kemampuan dari sebuah tetesan untuk membasahi permukaan atau seberapa luasan tetesan yang menyentuh permukaan padat disebut wettability. Ketika droplet menumbuk permukaan mampu mengalami penyebaran dan membentuk film tipis, droplet dapat didefinisikan memiliki kemampuan pembasahan yang kuat. Kemampuan pembasahan lemah apabila droplets pecah dan memercik menjadi butiran kecil sehingga hanya membasahi sebagian permukaan [4]. Wettability berkaitan erat dengan laju perpindahan kalor yang terjadi antara sebuah droplet dengan permukaan padat. Semakin luas daerah yang dibasahi oleh droplet maka semakin besar laju perpindahan kalornya [8].

Pada tumbukan droplet terdapat faktor penting yang mempengaruhi dinamika tumbukan droplet, dimana faktor tersebut dapat mempengaruhi kondisi droplet ketika menumbuk permukaan padat terpanasi. Beberapa kondisi droplet ketika menumbuk permukaan yaitu stick, rebound, spread, splash, boiling induced break up, break up dan rebound with break up [4]. Faktor penting tersebut adalah energi tumbukan yang direpresentasikan dengan bilangan Weber. Bilangan tersebut didefinisikan sebagai rasio antara inertia energy dengan surface tension energy [9]. Bilangan Weber bisa dikategorikan menjadi tiga region yaitu: rendah ( $\mathrm{We}<30$ ), sedang $(30<\mathrm{We}<80)$ dan tinggi ( $\mathrm{We}>80)$. Ito dkk. [10] melakukan percobaan tumbukan droplet pada bilangan Weber rendah hingga tinggi dan didapatkan bahwa pada bilangan Weber sedang droplet tidak mengalami disentrigasi tetapi menyebar saat tumbukan. Sebagai contoh pada proses pendinginan dari produksi logam (quenching), air disemprotkan ke permukaan logam panas dengan kecepatan rendah, dimana bilangan Weber mendekati daerah bilangan Weber sedang. Pada bilangan Weber sedang (medium) mampu mengalami seluruh dinamika droplet yang telah disebutkan sebelumnya kecuali menyiprat (splashing). Bilangan Weber yang tidak terlalu tinggi dengan kecepatan yang rendah, tetapi tetap memberikan pengaruh pada proses pendinginan [11].

Selain bilangan Weber, Hidaka dkk. [12] menggunakan waktu evaporasi sebagai karakteristik perpindahan kalor pada tumbukan droplets. Analisa dilakukan dengan mempelajari hubungan antara waktu evaporasi dengan temperatur permukaan pada kurva evaporasi. Tumbukan droplet diawali ketika droplet jatuh ke permukaan panas, kemudian kontak langsung antara cair dan padat terjadi. Perpindahan kalor konduksi terjadi secara pertama kali dari permukaan ke liquid film dan kemudian evaporasi terjadi dari permukaan liquid film, dengan kondisi temperatur permukaan sedang. Temperatur permukaan meningkat akan menurunkan waktu evaporasi hingga titik minimum. Temperatur permukaan dimana mengalami waktu evaporasi terendah ini disebut dengan titik wetting limit temperature. Jika temperatur permukaan terus meningkat hingga diatas titik wetting limit temperature, maka film uap akan terbentuk dan waktu evaporasi meningkat hingga sampai puncaknya. Kondisi puncak waktu evaporasi setelah melewati titik wetting limit temperature disebut titik leidenfrost. Setelah melewati titik 
leidenfrost maka akan memasuki kondisi perpindahan kalor sepenuhnya melalui film uap dan waktu evaporasi mulai turun kembali.

Dinamika droplet telah dianalisa dengan berbagai macam pendekatan karakteristik perpindahan kalor seperti perhitungan waktu evaporasi yang telah dilakukan Hidaka dkk. [12], dan Huang dan Carey [13], perhitungan spreading ratio yang telah dilakukan Bernadin dkk. [9], Tang dkk. [14], Deendarlianto dkk. [15], Chaves dkk. [16], Ito dkk. [17] dan Zhao dkk. [18], perhitungan efektivitas pendinginan droplet yang dilakukan oleh Pasandideh dkk. [19], pengamatan waktu kontak droplet dengan permukaan oleh Moon dkk. [20] dan pengamatan sudut kontak telah dilakukan oleh Venkatesan dkk. [21] serta Mitra dkk. [22]. Hasil dari penelitian mereka merupakan bentuk kuantitasi dari kemampuan penyerapan kalor oleh droplet dalam menumbuk permukaan padat yang dipanaskan.

Pada penelitian ini proses spray cooling didekati dengan sebuah proses multiple droplets dan tidak dengan single droplet. Bentuk penyederhanaan ini seperti diilustrasikan pada Gambar 1.

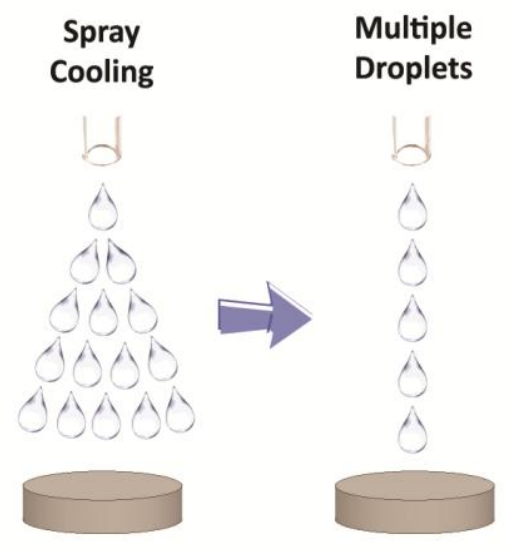

Gambar 1. Skema Spray Cooling dan Multiple Droplet

Dari proses multiple droplet yang divariasikan pada berbagai nilai tetesan, kemudian besarnya koefisien perpindahan kalor konveksi multiple droplet dapat ditentukan. Pengamatan dilakukan pada permukaan datar stainless steel dengan temperatur permukaan divariasikan pada $100^{\circ} \mathrm{C}-$ $200^{\circ} \mathrm{C}$ dan bilangan Weber sedang. Pada penelitian ini juga diamati pengaruh temperatur permukaan dan frekuensi tetesan pada maximum spreading ratio, laju perpindahan kalor dari spesimen ke droplet dan koefisien perpindahan kalor konveksi pada tumbukan multiple droplets.

\section{METODE PENELITIAN}

Eksperimen multiple droplet dilaksanakan dengan menggunakan alat uji eksperimen yang berada di Laboratorium Perpindahan Kalor dan Massa dan Laboratorium Mekanika Fluida, Departemen Teknik Mesin dan Industri, Fakultas Teknik, Universitas Gadjah Mada. Skema alat uji yang digunakan seperti ditunjukkan pada Gambar 2. Seperti terlihat pada Gambar 2, eksperimen dilakukan dengan meletakkan tangki yang berisi air destilasi, kemudian dialirkan pada selang silicon yang alirannya diatur dengan solenoid valve dan control valve.

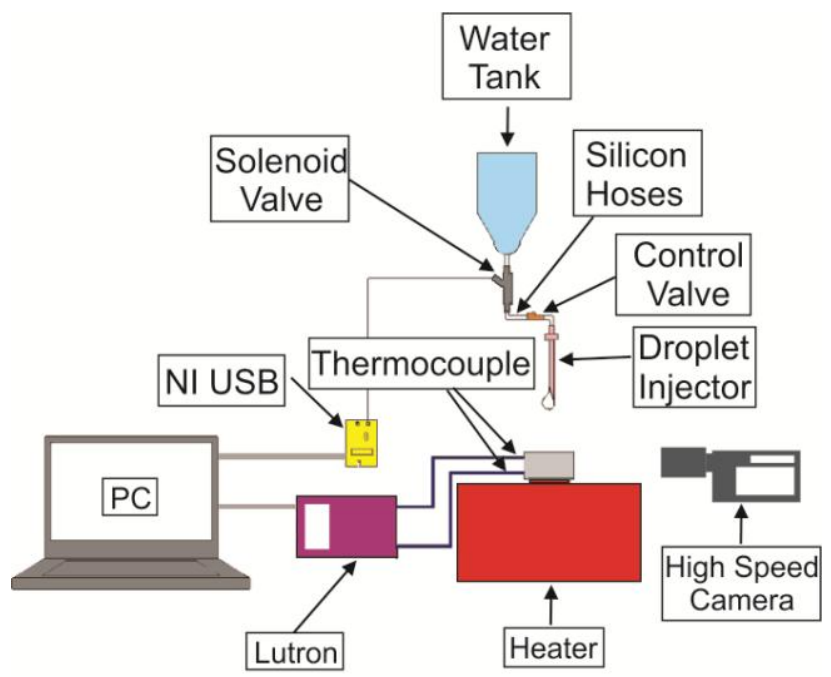

Gambar 2. Skema Alat Uji Eksperimen

Droplet diinjeksi hingga menumbuk permukaan spesimen panas yang diatur pada temperatur permukaannya $100,120,140,160,180$ dan $200^{\circ} \mathrm{C}$. Spesimen yang digunakan berupa stainless steel yang berbentuk silinder berdiameter $50 \mathrm{~mm}$. Fluida yang digunakan adalah aquades murni. Temperatur permukaan diukur menggunakan termokopel jenis $\mathrm{K}$. Untuk mengukur temperature pada spesimen, dipasang termokopel sejumlah dua buah dengan 
letak pemasangan termokopel ditunjukkan pada Gambar 3. Pada saat proses pengambilan data, harus dipastikan bahwa termokopel atas dan bawah menunjukkan temperatur yang sama sebelum ditumbuk oleh droplets. Hal ini dilakukan untuk mengukur beda penurunan temperatur spesimen bagian atas dan bawah, yang nanti akan menjadi dasar perhitungan perpindahan kalor dari spesimen ke droplets.

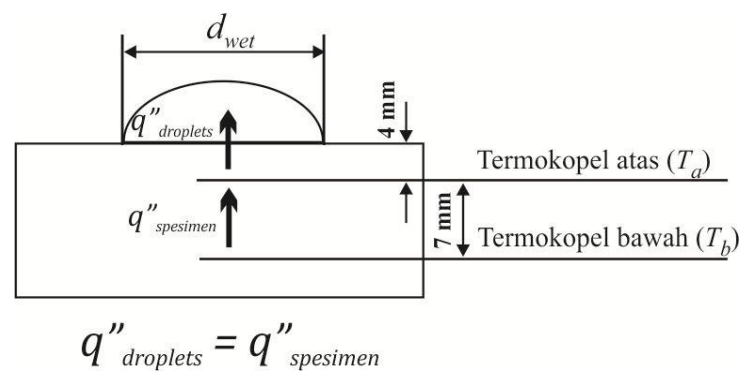

Gambar 3. Skema Pemasangan Termokopel pada Spesimen.

Penetesan droplets dilakukan dengan menggunakan gaya gravitasi, dengan tangki air dibuka pada tekanan atmosfer. Sehingga peletakan tangki air akan mempengaruhi nilai laju penetesan atau frekuensi droplets. Pada studi ini, variabel pengujian adalah frekuensi tetesan dengan nilai sebesar 250, 400 dan 600 tetes/menit, yang didapatkan dengan meletakan tangki dengan ketinggian 1, 1,5 dan $2 \mathrm{~m}$; berdasarkan perhitungan energi mekanik. Hal ini dilakukan untuk mendapatkan variasi frekuensi tetesan rendah, sedang dan tinggi. Perpedaan interval waktu penumbukan antar frekuensi tetesan ditunjukkan pada Gambar 4. Kondisi diameter awal droplet adalah sebesar $2,75 \mathrm{~mm}$. Pemilihan bilangan Weber adalah 52,6 (level sedang), dengan menggunakan perhitungan kecepatan droplet jatuh bebas, maka ketinggian penetesan dapat dihitung. Pada pengujian ini, ketinggian penetesan dilakukan pada $70 \mathrm{~mm}$.

Pengambilan data diawali dengan membuka droplet injector valve, kemudian droplet mengalir dan menumbuk permukaan specimen. Pada saat proses tumbukan, dilakukan perekaman peristiwa tumbukan droplets dan pengukuran penurunan temperatur permukaan spesimen. Waktu pembukaan droplet injector valve dikontrol dengan bantuan perangkat data akuisisi National Instrument. Pada eksperimen ini, jumlah tumbukan yang digunakan adalah 20 droplets pada seluruh variabel yang diuji. Agar massa total droplet yang dikeluarkan selalu sama, maka diatur waktu pembukaan solenoid valve agar menghasilkan jumlah droplet sesuai yang diinginkan. Frekuensi tetesan 250 tetes/menit penetesan dilakukan selama 4,96 detik, frekuensi tetesan 400 tetes/menit penetesan dilakukan selama 3,24 detik dan frekuensi tetesan 600 tetes/menit penetesan dilakukan selama 2 detik untuk menghasilkan jumlah droplets sebanyak 20 droplets.

Dinamika tumbukan droplets diamati dengan menggunakan high speed video camera dengan kecepatan pengambilan gambarnya 1000 frame/detik. Penurunan temperatur spesimen dicatat dengan menggunakan data akuisisi Lutron yang disambungkan dengan kabel data ke komputer. Sehingga data penurunan temperatur spesimen seluruhnya dapat terbaca oleh komputer.

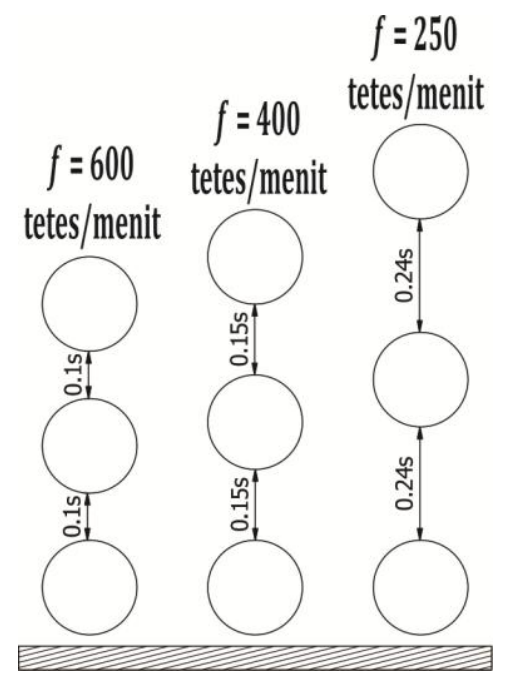

Gambar 4. Interval Waktu Tumbukan berbagai Variasi Frekuensi Tetesan.

Dari hasil eksperimen, didapatkan video dari proses tumbukan droplets dan data penurunan temperatur termokopel atas dan bawah. Data tersebut kemudian dianalisa dengan pengukuran diameter pembasahan dan perhitungan perpindahan kalor. Karakteristik pembasahan droplets akan dikuantitasikan dengan cara 
membagi diameter pembasahan ( $\left.\boldsymbol{d}_{\text {wet }}\right)$ dengan diameter awal $\left(\boldsymbol{d}_{\mathbf{0}}\right)$. Pengukuran diameter pembasahan dari seluruh gambar yang dimulai dari penetesan awal hingga menguap seluruhnya. Teknik image processing digunakan untuk menghitung diameter awal dan pembasahan droplet dari gambar tumbukan droplets. Hal tersebut dilakukan dengan cara melakukan metode thresholding pada gambar. Thresholding merupakan metode segmentasi citra, dari citra abu-abu. Thresholding dapat digunakan untuk membuat citra biner. Pada proses thresholding, akan ditentukan nilai thresholding jika gambar memiliki nilai thresholding lebih besar dari nilai thresholding yang telah ditentukan maka gambar tersebut akan digunakan sebagai objek. Dengan asumsi objek tersebut lebih gelap (abu-abu) dari latar belakangnya. Pengukuran diameter awal dan diameter pembasahan dengan teknik image processing seperti ditunjukkan pada Gambar 5.
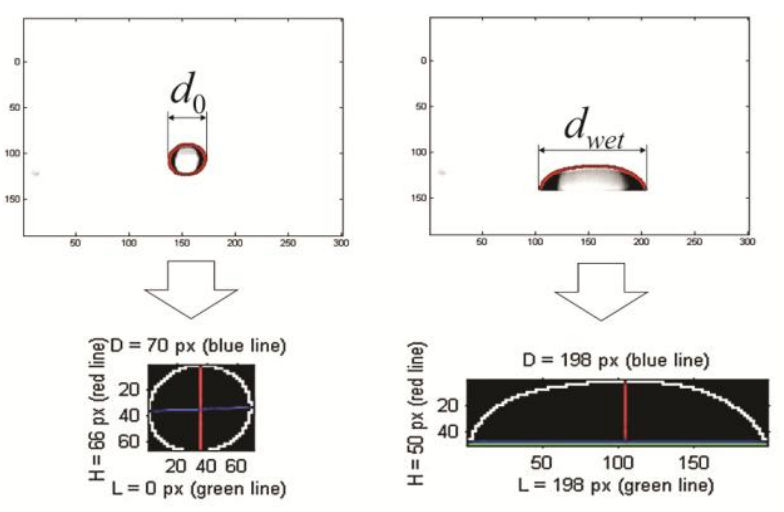

Gambar 5. Pengukuran Diameter Droplet dengan Teknik Image Processing

\section{HASIL DAN PEMBAHASAN}

Pada penelitian ini dicari nilai koefisien perpindahan kalor konveksi multiple droplets dengan pengaruh frekuensi tetesan. Fenomena dan dinamika droplet diamati guna mengetahui kondisi droplet ketika menumbuk serta mempelajari pengaruhnya terhadap nilai kofisien perpindahan kalor konveksi. Deendarlianto dkk. [8] menyatakan bahwa terdapat titik wetting limit temperature, dimana droplet mulai terangkat disebabkan tingginya temperatur. Sehingga visualisasi dan perhitungan laju perpindahan kalor dari permukaan droplet diamati untuk mengetahui kondisi droplet.

Hasil pengamatan menunjukkan ketika droplet menumbuk akan mengalami pembasahan maksimum dimana droplet mampu melebar dan membasahi permukaan. Hal tersebut merupakan kemampuan droplet dalam membasahi permukaan. Kemampuan pembasahan droplet tersebut akan dikuantitasikan agar mudah dalam menganalisanya. Pengukuran dilakukan dengan cara membandingkan diameter pembasahan $\left(\boldsymbol{d}_{\boldsymbol{w e t}}\right)$ dengan diameter awal droplet $\left(\boldsymbol{d}_{\mathbf{0}}\right)$ atau disebut dengan spreading ratio $\left(\boldsymbol{\beta}=\boldsymbol{d}_{\text {wet }} / \boldsymbol{d}_{\mathbf{0}}\right) \quad$ [16]. Semakin besar spreading ratio droplet akan meningkatkan luasan kontak dari droplets ke permukaan spesimen. Hal ini juga meningkatkan transfer kalor dari permukaan spesimen ke droplets. Selanjutnya, perbandingan maximum spreading ratio antara tumbukan multiple droplets dengan frekuensi 250, 400 dan 600 tetes/menit bisa ditentukan dan dianalisa.

Gambar 6 menunjukkan kurva maximum spreading ratio, temperatur permukaan diplot terhadap maximum spreading ratio dengan frekuensi tetesan sebagai variabel. Hasil eksperimen menunjukkan bahwa maximum spreading ratio meningkat seiring dengan meningkatnya temperatur permukaan. Hal ini terjadi karena tegangan permukaan droplets menurun seiring dengan kenaikan temperatur permukaan, sehingga gaya tarik droplets menurun. Hal tersebut menyebabkan droplets tidak mampu menahan untuk tidak terjadinya spreading yang meningkatkan maximum spreading ratio. Didapatkan bahwa, peningkatan maximum spreading ratio terjadi hanya pada temperatur permukaan $100^{\circ} \mathrm{C}$ hingga $160^{\circ} \mathrm{C}$ kemudian menurun pada $180^{\circ} \mathrm{C}$ dan $200^{\circ} \mathrm{C}$. Pada temperatur permukaan $160^{\circ} \mathrm{C}$ ditandai sebagai kondisi puncak dari daerah pembasahan terluas. Kemudian daerah pembasahan menurun pada temperatur permukaan yang lebih tinggi. Dari hasil observasi didapatkan bahwa, pada temperatur permukaan $180^{\circ} \mathrm{C}$ spreading yang terjadi telah mengalami penguapan yang cepat sehingga bagian tepian tipis droplet mengalami penyusutan. Tabel 1 menunjukan visualisasi dimana kondisi $180^{\circ} \mathrm{C}$ 
mengalami pengecilan spreading karena tingginya heat flux dari permukaan. Hasil pengujian juga menunjukkan bahwa, pada temperatur permukaan sebesar $200^{\circ} \mathrm{C}$ memiliki maximum spreading ratio paling rendah, hal ini dikarenakan temperatur permukaan yang sangat tinggi sehingga memunculkan sedikit film uap yang mampu mengangkat sebagian droplets. Hal ini juga diperkuat dari gambar dinamika droplet yang ditunjukkan pada Tabel 1, dimana pada temperatur permukaan $200^{\circ} \mathrm{C}$, droplet terlihat mulai sulit membasahi permukaan.

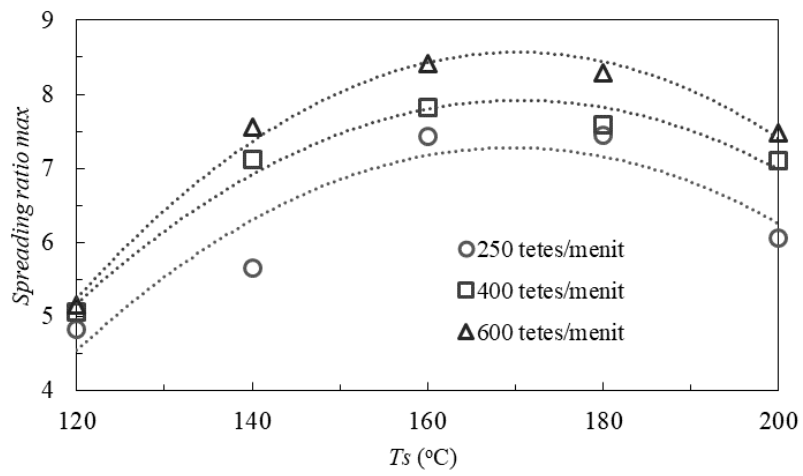

Gambar 6. Spreading ratio maksimum pada permukaan panas dengan variasi frekuensi tetesan 250, 400 dan 600 tetes/menit.

Tabel 1. Visualisasi spreading maksimum pada $f=$ 250 tetes/menit.

Droplets spreading maksimum dengan $f=250$ tetes/menit

$\frac{-\frac{120^{\circ} \mathrm{C}}{-\frac{140^{\circ} \mathrm{C}}{180^{\circ} \mathrm{C}}}-\frac{\frac{1000}{160^{\circ} \mathrm{C}}}{200^{\circ} \mathrm{C}}}{-\frac{100}{2}}$

Gambar 6 juga menunjukkan bahwa maximum spreading ratio mengalami peningkatan dengan meningkatnya frekuensi tetesan. Pada temperatur permukaan $100^{\circ} \mathrm{C}$ dan $120^{\circ} \mathrm{C}$ (dimana droplet masih mengalami seluruh dinamika tumbukan antara lain spreading, maximum spreading dan recoiling) dan frekuensi tinggi (400 dan 600 tetes/menit), terlihat droplet memiliki spreading ratio yang besar. Hal ini dikarenakan pada frekuensi tetesan yang tinggi, droplets telah mampu menumbuk sisa droplets yang masih berosilasi dan belum mencapai kesetimbangan. Sedangkan pada frekuensi tetesan rendah (250 tetes/menit), sisa droplets yang akan tertumbuk telah mencapai kesetimbangan. Hasil pengujian juga menunjukkan bahwa, frekuensi tetesan juga mampu memperbesar spreading ratio pada temperatur permukaan $140^{\circ} \mathrm{C}$ hingga $200^{\circ} \mathrm{C}$. Hal ini disebabkan karena, pada frekuensi tetesan tinggi, droplets mampu lebih cepat menumbuk sebelum bagian tepian tipis droplets menyusut. Pada temperatur permukaan $200^{\circ} \mathrm{C}$, frekuensi tetesan tinggi mampu meredam loncatan-loncatan pada droplets yang disebabkan mulainya muncul sedikit lapisan film yang mampu melevitasi droplets.

Pada studi ini, laju perpindahan kalor ke droplet dihitung dengan mengasumsikan besarnya heat flux yang dilepas oleh spesimen terserap seluruhnya ke droplet $q^{\prime \prime}{ }_{\text {spesimen }}=q^{\prime \prime}$ droplet. $_{\text {. Ilustrasi }}$ proses perpindahan kalor dari spesimen ke droplet seperti ditunjukkan pada Gambar 3. Perhitungan heat flux spesimen didapatkan dari perbedaan penurunan termokopel atas dan bawah seperti yang ditunjukkan pada Gambar 7. Hal tersebut terjadi ketika droplet menumbuk spesimen dengan adanya tebal spesimen dan konduktivitas termal, akan menyebabkan beda penurunan termokopel atas dan termokopel bawah. Gambar 7 juga menunjukkan bahwa, termokopel atas mengalami penurunan temperatur lebih curam dibandingkan dengan termokopel bawah.

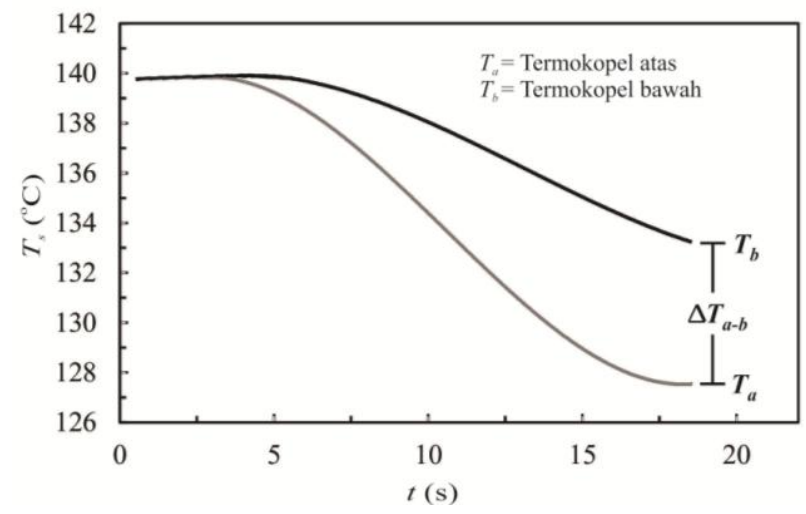

Gambar 7. Hasil Pengukuran Beda Temperatur Termokopel Atas $\left(T_{a}\right)$ dan Bawah $\left(T_{b}\right)$. 
Laju perpindahan kalor droplet dihitung dengan pendekatan laju perpindahan kalor dari termokopel bawah ke termokopel atas yang melalui daerah pembasahan droplet yang berkontak dengan permukaan spesimen dengan Persamaan (1).

$\dot{q}_{\text {droplets }}=k \frac{\left(\Delta T_{a-b}\right)_{\text {avg }}}{\Delta x} \pi \frac{1}{4} d_{w e t}^{2}$

Dimana $q$ droplet adalah laju perpindahan kalor dari spesimen ke droplets (W), $k$ adalah konduktivitas thermal stainless steel (W/m $\square \mathrm{K}$ ), $\left(\Delta \boldsymbol{T}_{\boldsymbol{a}-\boldsymbol{b}}\right)_{\boldsymbol{a v g}}$ adalah rata-rata beda penurunan temperatur termokopel atas dan bawah (K), dan $\Delta x$ merupakan jarak antara termokopel atas dan bawah $(0,015 \mathrm{~m})$.

Hasil perhitungan laju perpindahan kalor pada berbagai nilai temperatur permukaan dan variasi frekuensi tetesan droplet disajikan dalam Gambar 8 .

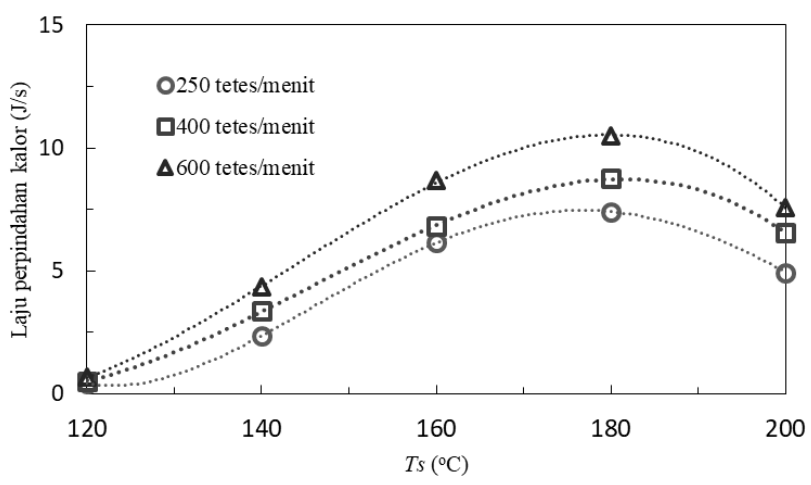

Gambar 8. Besarnya $q$ dengan Variasi Frekuensi

Tetesan 250, 400 dan 600 tetes/menit.

Gambar 8 menunjukkan bahwa, besarnya laju perpindahan kalor meningkat seiring dengan peningkatan temperatur permukaan. Peningkatan laju perpindahan kalor yang terjadi dikarenakan meningkatnya luasan pembasahan yang lebih besar disetiap peningkatan temperatur permukaan, terkecuali pada temperatur permukaan $200^{\circ} \mathrm{C}$. Pada temperatur permukaan $200^{\circ} \mathrm{C}$, terjadi penurunan laju perpindahan kalor dikarenakan adanya penurunan daerah pembasahan. Puncak laju perpindahan kalor tertinggi terjadi pada temperatur permukaan $180^{\circ} \mathrm{C}$, walaupun daerah pembasahan pada $T_{s}=180^{\circ} \mathrm{C}$ lebih kecil dibandingkan dengan temperatur permukaan luasan pembasahan pada $T_{s}=160^{\circ} \mathrm{C}$, akan tetapi pada temperatur permukaan $180^{\circ} \mathrm{C}$ memiliki heat flux yang lebih besar. Hasil eksperimen juga menunjukkan bahwa, frekuensi tetes yang tinggi mampu memberikan laju perpindahan kalor yang lebih besar disebabkan mampu memberikan daerah pembasahan dan heat flux yang lebih besar. Pada temperatur permukaan rendah sekitar dibawah $120^{\circ} \mathrm{C}$, peningkatan frekuensi tetesan belum memberikan peningkatan laju perpindahan kalor yang signifikan. Sedangkan laju perpindahan kalor pada temperatur permukaan lebih tinggi dari $140^{\circ} \mathrm{C}$, mampu memberikan perbedaan yang signifikan. Pada frekuensi tetesan tinggi mampu memberikan daerah pembasahan yang lebih luas, hal ini dikarenakan dengan frekuensi tetesan yang tinggi, multiple droplet akan mampu menumbuk sisa droplet sebelum terjadinya penyusutan diameter droplet.

Koefisien perpindahan kalor konveksi dihitung untuk menggambarkan karakteristik perpindahan kalor multiple droplet. Pada proses tumbukan droplet terjadi dan temperature permukaan di atas temperatur saturasi droplet, maka terjadi proses penguapan (perubahan fase dari cair ke uap). Sehingga, selama proses tumbukan, banyak gelembung yang muncul dari permukaan pada tumbukan multiple droplet. Sehingga, proses perpindahan kalor konveksi mendominasi proses perpindahan kalor pada proses tumbukan droplet. Berdasarkan asumsi sebelumnya yaitu heat flux yang dilepas spesimen sama dengan heat flux yang diterima oleh droplets, maka Persamaan (2) berikut digunakan untuk menghitung koefisien perpindahan kalor konveksi.

$h=\frac{k \frac{\left(\Delta T_{a-b) a v g}\right.}{\Delta x}}{\Delta T_{s a t}}$

Dimana $h$ adalah koefisien perpindahan kalor konveksi $\quad\left(\mathrm{W} / \mathrm{m}^{2} \square \mathrm{K}\right) . \quad \Delta \boldsymbol{T}_{\text {sat }}$ adalah beda temperatur droplet dari temperatur awal $\left(27^{\circ} \mathrm{C}\right)$ hingga temperatur saturasi droplet pada tekanan atmosfer $\left(100^{\circ} \mathrm{C}\right)$. 
Gambar 9 merupakan kurva koefisien perpindahan kalor konveksi untuk semua temperatur permukaan yang diuji dengan berbagai frekuensi tetesan. Terlihat bahwa dengan meningkatnya temperatur permukaan, mampu meningkatkan koefisien perpindahan kalor konveksi hingga temperatur permukaan $180^{\circ} \mathrm{C}$. Juga terlihat pada Gambar 9 bahwa, pada temperatur permukaan $200^{\circ} \mathrm{C}$ terjadi penurunan koefisien perpindahan kalor konveksi disebabkan munculnya film uap sehingga droplet mulai sulit menyentuh permukaan. Berdasarkan visualisasi fenomena droplet pada Tabel 1 terlihat bahwa droplet telah mulai terangkat dan sulit terkontak dengan permukaan, sehingga perpindahan kalor secara radiasi ikut berperan pada perpindahan kalor dari spesimen ke droplet. Munculnya gelembung disebabkan lepasnya udara yang terperangkap pada pori-pori permukaan spesimen. Deendarlianto dkk. [8] menyatakan bahwa suhu permukaan yang jauh lebih tinggi dari pada suhu mendidih air, tekanan cairan lebih rendah dari pada tekanan saturasinya. Karena itu, kavitasi mengambil peran dalam proses ini. Fenomena yang serupa juga dijelaskan oleh [23]. Meningkatnya frekuensi tetesan memberikan peran dalam pengingkatan koefisien perpindahan kalor konveksi. Frekuensi tetesan tinggi mampu menumbuk droplet yang masih mengalami osilasi sehingga mampu memperkuat kontak droplet dengan spesimen. Terutama pada temperatur tinggi frekuensi tinggi mampu segera menumbuk droplet untuk meminimalisir cipratan yang akan menyebabkan berkurangnya massa droplet.

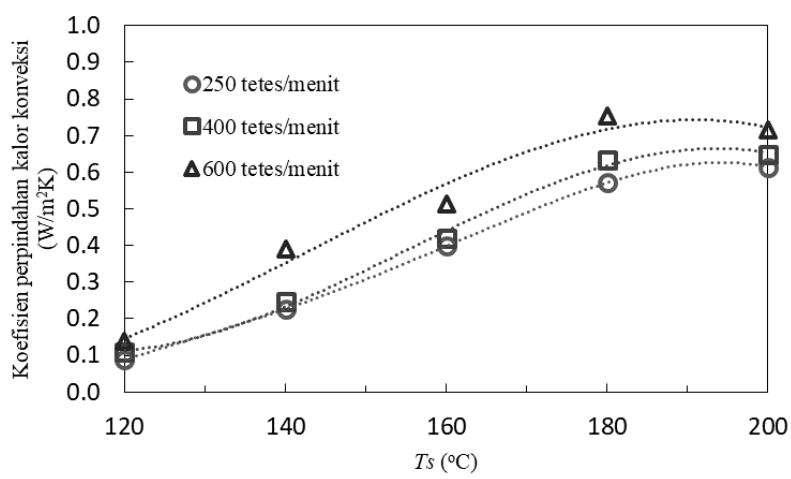

Gambar 9. Nilai $h$ dengan Variasi Frekuensi Tetesan 250, 400, dan 600 tetes/menit.

\section{KESIMPULAN}

Studi eksperimental multiple droplet yang menumbuk permukaan stainless steel terpanasi dengan variasi frekuensi tetesan dan temperatur permukaan telah dilakukan. Frekuensi tetesan divariasikan 250, 400 dan 600 tetes/menit dan temperatur permukaan pada 120 hingga $200^{\circ} \mathrm{C}$. Pengaruh dari variable frekuensi tetesan pada spreading ratio, laju perpindahan kalor dan koefisien perpindahan kalor konveksi dipelajari dan dianalisa. Dari hasil eksperimen didapatkan bahwa meningkatnya frekuensi tetes mampu meningkatkan maximum spreading ratio, laju perindahan kalor dan koefisien perpindahan kalor konveksi. Didapatkan bahwa, dengan frekuensi tetesan tinggi dan pada temperatur permukaan rendah, multiple droplets mampu menumbuk droplet di permukaan yang masih mengalami osilasi. Sedangkan pada temperatur permukaan tinggi, multiple droplets tidak hanya mampu menumbuk droplet yang masih berosilasi tetapi juga mampu meredam cipratan atau loncatan droplet, sehingga akan meningkatkan kontak droplet terhadap permukaan. Selain itu disimpulkan bahwa, pengujian pada temperatur permukaan semakin tinggi mampu meningkatkan maximum spreading ratio hingga titik tertingginya pada temperatur permukaan $160^{\circ} \mathrm{C}$. Sedangkan laju perpindahan kalor dan koefisien perpindahan kalor konveksi juga mengalami peningkatan nilai seiring dengan meningkatnya temperatur permukaan tetapi memiliki kondisi puncak pada temperatur permukaan $180^{\circ} \mathrm{C}$. Pada penelitian ini titik wetting limit temperature terjadi pada temperatur permukaan $180^{\circ} \mathrm{C}$.

\section{UCAPAN TERIMA KASIH}

Penulis mengucapkan terimakasih atas sebagian dukungan finansial yang diberikan oleh Hibah Penelitian Departemen Teknik Mesin dan Industri, Fakultas Teknik, Universitas Gadjah Mada Tahun 2018 dengan Nomor Kontrak: 822/H1.17/TMI/LK/2018. 


\section{DAFTAR PUSTAKA}

[1] L.W. Jin, I. Pranoto, K.C. Leong dan J.C. Chai, "Parametric Study of Pool Boiling from Porous Graphite Foams in Dielectric Liquids", Proceedings of $3^{\text {rd }}$ International Conference on Thermal Issues in Emerging Technologies: Theory and Applications, 19-22 December 2010, Cairo, Egypt.

[2] I. Pranoto and K.C. Leong, "An Experimental Study of Flow Boiling Heat Transfer from Porous Foam Structures in a Channel", Applied Thermal Engineering, Vol. 70, pp.100-114, 2014.

[3] W.L. Cheng, W.W. Zhang, H. Chen dan L. Hu, "Spray Cooling and Flash Evaporation Cooling: The Current Developmnt and Application", Renewable and Sustainable Energy Reviews, Vol. 55, pp. 615-628, 2015.

[4] S.Y. Lee, dan S.U. Ryu "Recent Progress of Spray-Wall Interaction Research", The Japan Society of Mechanical Engineers, Vol. 20, pp. 1101-1117, 2006.

[5] J.D. Bernardin, I. Mudawar, C.B. Walsh dan E.I. Franses "Contact Angle Temperature Dependence for Water Droplets on Practical Aluminum Surfaces", International Journal of Heat and Mass Transfer, Vol. 40, pp. 10171033, 1996.

[6] J.D. Naber dan R.D. Reitz "Hydrodynamics of Droplet Impingement on Heated Surface", SAE-Techn, Paper No. 930919, 1993.

[7] K. Sienski, R. Eden, dan D. Schaefer "3-D Electronic Interconnect Packaging", IEEE Proceedings of Aerospace Applications Conference, pp. 363-373, 1996.

[8] Deendarlianto, T. Yasuki, H. Sumitorno, Indarto, A. Widyaparaga, S. Kamal, Purnomo, dan M. Kohno "Effect of Static Contact Angle on The Droplet Dynamics During The Evaporation of a Water Droplet on The Hot Walls", International Journal of Heat and Mass Transfer, Vol. 71, pp. 691-705, 2014.

[9] J.D. Bernardin, C.J. Stebbins dan I. Mudawar "Mapping of Impact and Heat Transfer Regimes of Water Drops Impinging on a Polished Surface", International Journal of Heat and Mass Transfer, Vol. 40, pp. 247-267, 1997.
[10] T. Ito, Y. Takata dan M.M.M Mousa "Studies on the Water Cooling Hot Surfaces (Analysis of Spray Cooling in The Region Associated with Film Boiling)", The Japan Society of Mechanical Engineers, Vol. 35, pp. 589-598, 1992.

[11] W.H. Mitrakusuma, S. Kamal, Indarto, M.D. Susila, Hermawan dan Deendarlianto. "The Dynamics of the Water Droplet Impacting onto Hot Solid Surfaces at Medium Weber Numbers", Heat and Mass Transfer, Vol. 53: 3085-3097, 2017.

[12] S. Hidaka, A. Yamashita dan Y. Takata "Effect of Contact Angle on Wetting Limit Temperature", Heat Transfer-Asian Research, Vol. 35, pp. 513-526, 2006.

[13] C.K. Huang dan V.P. Carey "The Effects of Dissolved Salt on the Leidenfrost Transition", International Journal of Heat and Mass Transfer, Vol. 50, pp. 269-282, 2007.

[14] C. Tang, M. Qin, X. Weng, X. Zhang, P. Zhang, J. Li dan Z. Huang "Dynamics of Droplet Impact on Solid Surface with Different Roughness", International Journal of Multiphase Fluid Flow, Vol. 96, pp. 56-69, 2017.

[15] Deendarlianto, T. Yasuki, M. Kohno, H. Sumitorno, T. Wakui, A.I. Majid, H.Y. Kuntoro, Indarto dan A. Widyaparaga "The Effect of the Surface Roughness on The Dynamic Behavior of The Successive Micrometric Droplet Impacting onto Inclined Hot Surfaces", International Journal of Heat and Mass Transfer, Vol. 101, pp. 1217-1226, 2016.

[16] H. Chaves, A.M. Kubitzek dan F. Obermeier "Dynamic Processes Occurring During The Spreading of Thin Liquid Film Prouduced by Drop Impact on Hot Walls", International Journal of Heat and Fluid Flow, Vol. 20, pp. 470-476, 1999.

[17] T. Ito, Y. Takata dan M.M.M Mousa "Studies on the Water Cooling Hot Surfaces (Analysis of Spray Cooling in The Region Associated with Film Boiling)", The Japan Society of Mechanical Engineers, Vol. 35, pp. 589-598, 1992. 
[18] P. Zhao, G.K. Hargrave, H.K. Versteeg, C.P. Garner, B.A. Reid, E.J. Long dan H. Zhao "The Dynamics of Droplet Impact on a Heated Porous Surface", Chemical Engineering Science, Vol. 190, pp. 232-247, 2018.

[19] M. Pasandideh, S.D. Aziz dan J. Mostaghimi "Cooling Effectiveness of A Water Drop Impinging on A Hot Surface", International Journal of Heat and Fluid Flow, Vol. 22, pp. 201-210, 2001.

[20] J.H. Moon, C.K. Choi, J.S. Allen dan S.H. Lee "Observation of a Mixed Regime for an Impinging Droplet on a Sessile Droplet", International Journal of Heat and Mass Transfer, Vol. 127, pp. 130-135, 2018.
[21] J. Venkatesan, S. Rajasekaran, A. Das dan S. Ganesan "Effects of Temperature-Dependent Contact Angle on the Flow Dynamics of an Impinging Droplet on a Hot Solid Substrate", International Journal of Heat and Fluid Flow, Vol. 62, pp. 282-298, 2016.

[22] S. Mitra, T.B.T. Nguyen, E. Doroodchi, V. Pareek, J.B. Joshi dan G.M. Evans "On Wetting Characteristics of Droplet on a Spherical Particle in Film Boiling Regime", Chemical Engineering Science, Vol. 149, pp. 181-203, 2016.

[23] S. Chandra dan C.T. Avedisian "On the Collision of a Droplet with a Solid Surface", Proceedings of the Royal Society A, Vol. 432, pp. 13-41, 1991. 